\title{
Measuring, simulating and optimizing current LED phosphor systems to enhance the visual quality of lighting
}

\author{
Charlotte Bois ${ }^{1,2^{*}}$, Peter Bodrogi ${ }^{2}$, Tran Quoc Khanh ${ }^{2}$ and Holger Winkler ${ }^{1}$
}

\author{
* Correspondence: \\ boischarlotte@hotmail.fr \\ ${ }^{1}$ Merck KGaA, Frankfurter Straße \\ 250, 64293 Darmstadt, Germany \\ 2Laboratory of Lighting Technology, \\ Technische Universität Darmstadt, \\ Hochschulstraße 4a, 64289 \\ Darmstadt, Germany
}

\begin{abstract}
Lighting engineering aspects of light emitting diodes (LEDs) with down converting phosphors (phosphor converted LEDs or PC-LEDs) were investigated by building sample PC-LEDs, measuring their spectral emission physically and simulating them with a software. This article describes the influence of the phosphors' chemical, physical and technological properties on some well-established and widely used measures of visual lighting quality including luminous efficacy and the color rendering index. The dependence of these measures on YAG and LuAG phosphor particle size and activator concentration in the PC-LEDs is dealt with. Light sources of superior lighting quality can be obtained by mixing several phosphors. Hence, the mixture of a green and red phosphor system was also studied for a set of real PC-LED light sources and their simulations. Two green and two red phosphors are considered in this study. To predict and optimize the lighting quality of PC-LEDs with a reasonable accuracy, a usable input shall be provided for the simulation software assuming the understanding of the emission mechanisms. To validate our simulation results, the PC-LEDs' measured spectral emission characteristics were compared with their simulated counterparts. The measurement and simulation of spectral power distributions contribute to the understanding of new phosphor mixtures. The present simulation method turned out to be usable to optimize the target parameters of the PC-LED (luminous efficacy, white tone quality and color quality of the illuminated colored objects).
\end{abstract}

Keywords: Phosphor; LED; PC-LED; Particle size; Phosphor mixture; Spectral power distribution; Simulation; Color rendering; Luminous efficacy; LightTools

\section{Background}

Energy saving and environmental considerations have oriented the efforts of light source manufacturers towards alternative illumination solutions. The development of energy efficient lighting devices that also provide a high visual lighting quality for general lighting user constitutes an important challenge. In the last decades, research in the area of solid state lighting achieved considerable advances [1]. LEDs proved to be an innovative and promising technology designed to revolutionize the lighting market [2]. Today's high-end LED light sources provide high luminous efficacy, high color quality, stability and long lifetime [3].

(c) 2014 Bois et al.; licensee Springer. This is an Open Access article distributed under the terms of the Creative Commons Attribution License (http://creativecommons.org/licenses/by/2.0), which permits unrestricted use, distribution, and reproduction in any medium, provided the original work is properly credited. 
White light can be obtained by adding the emission of blue, green and red LEDs. The association of a pumping UV LED and phosphors is an alternative technique [4]. The combination of powerful blue LEDs with broad emitting phosphors [5] enables to create so-called phosphor-converted LEDs (PC-LEDs) of promising light output and quality at an affordable price. As the latter approach has gained momentum in industry, PC-LEDs were chosen to be investigated in this paper.

The modelling of PC-LED emission spectra requires considering the physical interactions between the constituting elements, the LED chip and the phosphor. The PCLED's emission spectra and their visual lighting quality properties are strongly influenced by phosphor characteristics, its chemical composition or synthesis method. In this article, phosphor particle size in narrow particle size distribution YAG and LuAG phosphors were first considered to optimize the PC-LED's visual quality of lighting. The impact of YAG phosphor particle size on PC-LED light output [6-8] was reported in literature. However, these investigations were conducted on phosphors from different manufacturers hence it is difficult to compare them. Also, phosphor particle morphology in these previous studies was highly non-spherical.

The influence of phosphor particle size distribution (PSD) on the PC-LEDs' properties made of YAG phosphor was discussed in detail [9]. The present paper is intended to extend these considerations by measuring a set of dedicated PC-LEDs built from narrow phosphor particle size distributions and extracted from single synthesis batches of YAG and another garnet phosphor, LuAG. In the current study, a further chemical parameter, cerium activator concentration was also varied in the LuAG LEDs together with simultaneously varying particle size. The effect of these phosphor variations on the spectral power distributions of the PC-LED light source will be reported in this paper.

Then, four different phosphor mixtures of high visual lighting quality containing a green phosphor and a red-orange phosphor will be considered. Here again, sample PC-LEDs were built, measured and simulated. Accuracy limitations of the simulation will beanalyzed in terms of the differences of the measures of visual lighting quality between measurement and simulation.

\section{Method}

A comprehensive, interdisciplinary method was developed to investigate the impact of different phosphors on the PC-LEDs' properties. The principle is described in the flowchart of Figure 1. The method represents a combined view of chemical, physical, technological and simulation aspects. The method is based on the production of a set of sample PC-LEDs in a first step. This approach starts by exploring the chemical parameters of the phosphors. An analysis is performed on the sample PC-LEDs madefrom different phosphors varying in chemical composition, activator concentration and diverse phosphor mixture involved in down conversion. A phosphor system of two green and two red-orange phosphors was used to build sample PC-LEDs with a phosphor mixture. The spectral power distributions of these PC-LEDs were measured.

Particle size distribution represents a significant physical parameter influencing the PC-LEDs' lighting properties. Particle size distribution was measured with a 


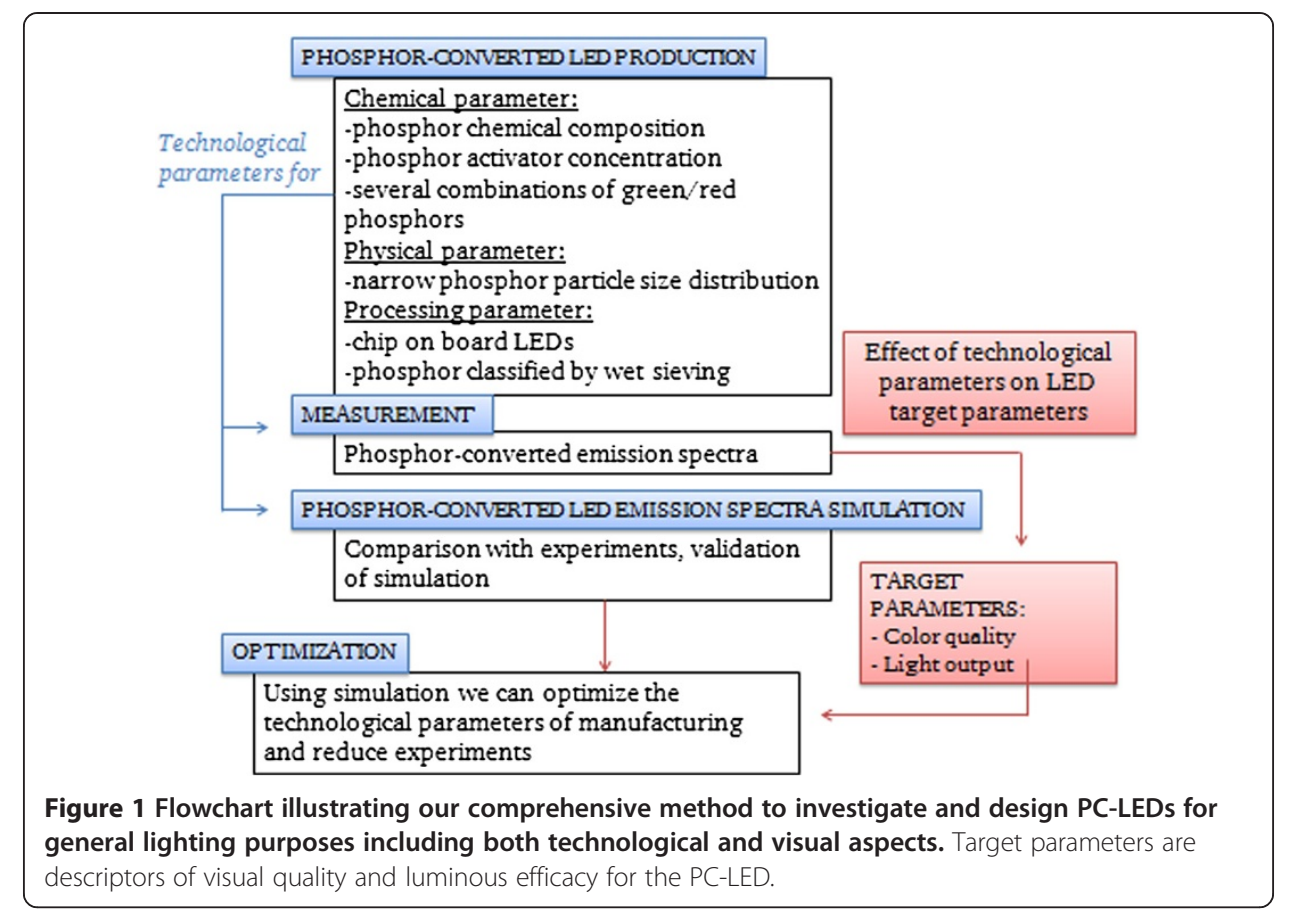

single-particle optical sizing system (AccuSizer 780/SIS, PSS Nicomp). The influence of particle size on YAG and LuAG LEDs was studied. Phosphors were classified by particle size following a sieving process. Blue chip-on-board LED light sources were used as a basis to build the PC-LEDs. Blue LEDs emit with a peak wavelength at $441 \mathrm{~nm}$ and a luminous flux of $5 \mathrm{~lm}$. LEDs are operated at constant forward current of $350 \mathrm{~mA}$, with an active cooling system imposing $25^{\circ} \mathrm{C}$. The phosphor was mixed with a transparent silicone binder (OE 6550, Dow Corning) and stirred to obtain homogeneous slurry. The latter still liquid was finally poured in a ring surrounding the blue LED. The volume to fill up with phosphor and silicone binder mixture is $40 \mathrm{~mm}^{3}$. After one hour curing at $150^{\circ} \mathrm{C}$ the silicone binder formed a solid layer enclosing phosphor particles resulting in the creation of conventional coated PC-LEDs. Precise weighting of slurry masses for each PC-LED ensures identical and reproducible phosphor layers and their luminescent properties in the PC-LEDs.

Absolute spectral power distributions were measured by the aid of an LED spectrometer (CAS 140, Instrument Systems) equipped with a $250 \mathrm{~mm}$ integrating sphere. It was possible to conclude about the influence of phosphor particle size on the spectral power distributions of our sample YAG and LuAG PC-LEDs. From the spectral power distributions, values of luminous efficiency and numeric descriptors of visual color quality of the light of the LED were calculated. The impact of the concentration of the Cerium activator was also studied for the case of our LuAG PC-LEDs as well as for the PC-LEDs with the green and red-orange phosphor combination.

Concerning our simulation method, the optical software LightTools ${ }^{\circ}$ was used based on Mie calculation to simulate our sample PC-LEDs measured in the experiment. Spectral power distributions (emission spectra) of the sample PC-LEDs were simulated using the measured photoluminescent data of the phosphors as input data for the simulation software. Simulated and measured spectral power distributions, color quality parameters 
and luminous efficacy values were compared to validate the simulation and determine its accuracy. The relevance of simulation is that it offers the possibility to optimize the technological parameters of the PC-LED for high color quality and high light output for the human light source user with a reduced number of experiments.

\section{Results and discussion}

\section{YAG}

The focus of this part of the paper concerns the investigation of a physical parameter, the influence of YAG $\left(\mathrm{Y}_{3} \mathrm{Al}_{5} \mathrm{O}_{12}\right.$ :Ce) phosphor particle size on the PC-LEDs' properties. Phosphor fractions were obtained after wet sieving of the same batch. The fractions exhibited therefore a narrow particle size distribution with ratios $\mathrm{d}_{90} / \mathrm{d}_{10}$ varying from 1.4 to 1.6. Cold white PC-LEDs with chromaticity coordinates $x=0.3075$ and $y=0.3130$ were produced for samples with median particle sizes $d_{50}$ of $11 \mu \mathrm{m}$ (YAG \#1), $15 \mu \mathrm{m}$ (YAG \#2), $28 \mu \mathrm{m}$ (YAG \#3), $31 \mu \mathrm{m}$ (YAG \#4), $33 \mu \mathrm{m}$ (YAG \#5) and $37 \mu \mathrm{m}$ (YAG \#6). The impact of the particle size on the phosphor photoluminescence properties and the description of the phosphor concentration in WLEDs have been reported previously [9]. LEDs of same chromaticity points require increasing phosphor concentrations with increasing phosphor particle sizes (in the range of 3 to 7 weight \%). Figure 2 shows the emission spectra of YAG for several particle sizes which confirms that the larger the phosphor particles are, the higher the emission and absorption intensities. White PCLEDs at the color temperature $T_{\mathrm{cp}}=7000 \mathrm{~K} \pm 200 \mathrm{~K}$ were achieved by crossing the locus of the daylight illuminants in the CIE $x, y$ chromaticity diagram. Spectral radiant flux distributions of these PC-LEDs are shown in Figure 3.

As can be seen from Figure 3, the white PC-LEDs' spectral radiant flux distributions are typical cool white LED spectra. The correlated color temperature (CCT) was set for all the LEDs to nearly the same mean value $(7000 \mathrm{~K} \pm 200 \mathrm{~K})$ in order to be able to compare them at a constant cold white tone. The radiance ratio between the blue portion of the pump LED and the yellow portion of fluorescence remained

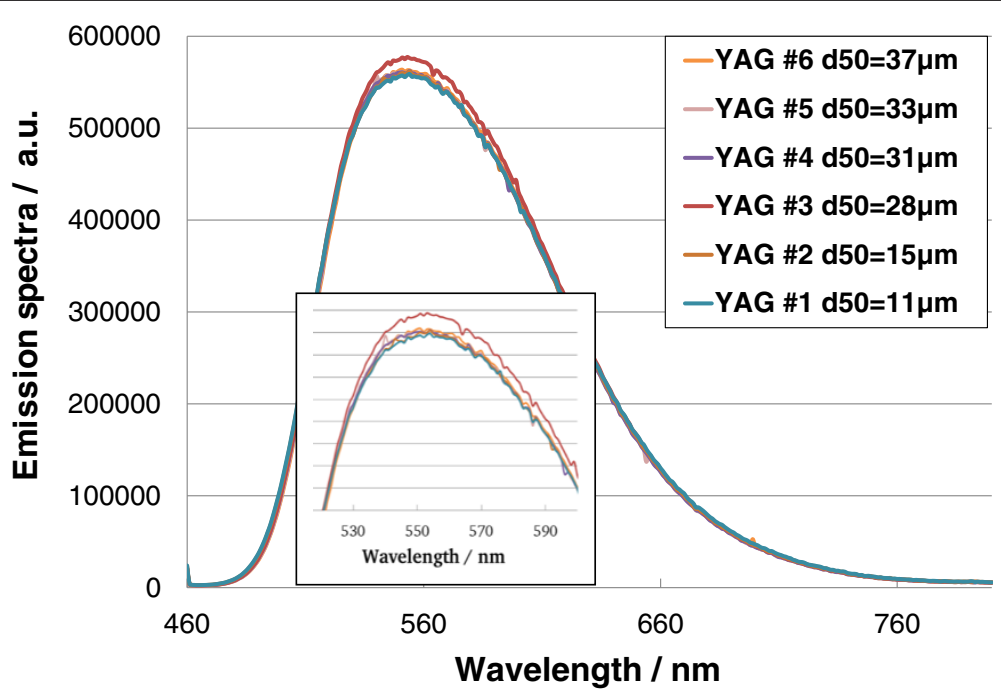

Figure 2 Emission spectra of YAG sieved fractions under excitation at $440 \mathrm{~nm}$ and zoom on the maximum 


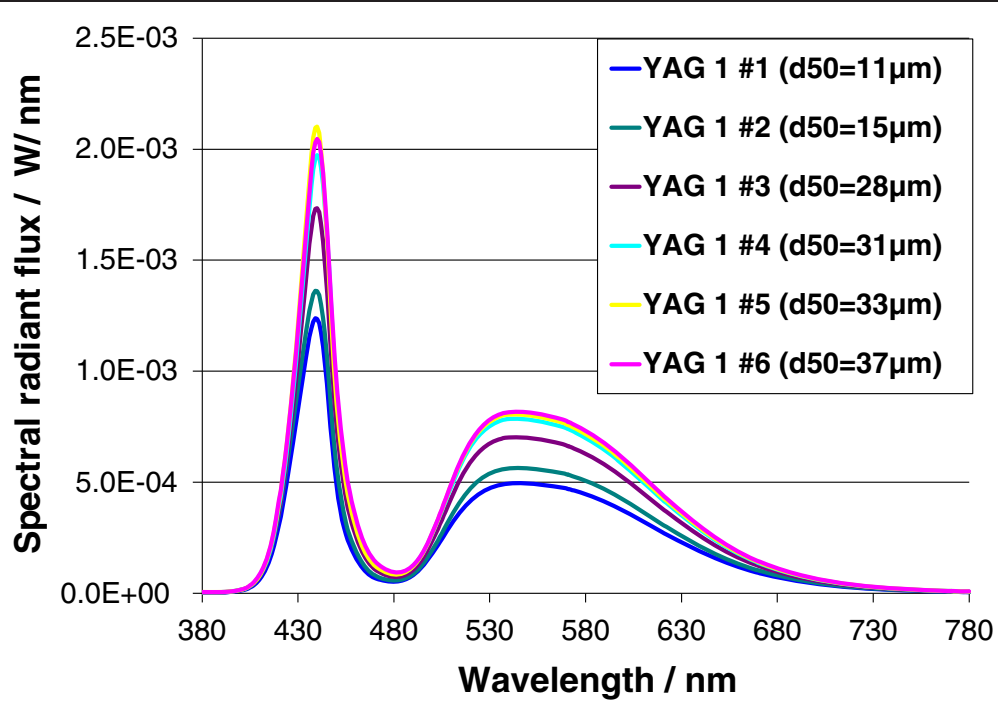

Figure 3 YAG PC-LEDs' spectral radiant flux distributions for different phosphor particle sizes.

approximately constant, independent of the phosphor particle size. Therefore, our test LEDs had not only approximately the same chromaticity but also similar color rendering properties. Color quality measures of these PC-LEDs of different phosphor particle sizes are listed in Table 1. These values are not affected by phosphor particle size significantly. These CRI values are visually too low for general lighting due to the lack of emission in the red part of the spectrum. Emission spectra also differ in their absolute intensity. Measured luminous efficacy of the sample PC-LEDs is plotted as a function of phosphor particle size in Figure 4.

As can be seen from Figure 4, luminous efficacy depends on phosphor particle size significantly. Luminous output decreases with a reduction in phosphor particle size possibly due to the fact that small particles scatter the light more strongly than large particles in every direction which results in backscattering. Backscattered radiation is absorbed in the blue LED chip which deteriorates luminous efficacy. Hence phosphor particle size is a determining factor of great impact on the light output of these PC-LEDs.

The above experimentally obtained data were simulated by using the LightTools ${ }^{\circ}$ program. Simulated and measured spectra as well as their differences are shown in Figure 5.

Table 1 Photometric values and color quality characteristics of measured and simulated YAG PC-LEDs

\begin{tabular}{|c|c|c|c|c|c|c|c|c|}
\hline & \multicolumn{2}{|c|}{ YAG 1} & \multicolumn{2}{|c|}{ YAG 2} & \multicolumn{2}{|c|}{ YAG 4} & \multicolumn{2}{|c|}{ YAG 6} \\
\hline & Simulated & Measured & Simulated & Measured & Simulated & Measured & Simulated & Measured \\
\hline $\mathrm{CCT} / \mathrm{K}$ & 6797 & 7260 & 6601 & 6424 & 6569 & 6819 & 5608 & 6091 \\
\hline CRI $R_{\mathrm{a}}$ & 76 & 75 & 76 & 74 & 77 & 74 & 71 & 72 \\
\hline CRI $R_{9}$ & 24 & 26 & 16 & 11 & 17 & 13 & -3 & -1 \\
\hline $\begin{array}{l}\text { luminous } \\
\text { flux/Im }\end{array}$ & 24.5 & 28.9 & 26.0 & 26.1 & 45.2 & 45.9 & 44.7 & 46.9 \\
\hline$\Delta u^{\prime} v_{\text {wtq }}^{\prime}$ & 0.027 & 0.025 & 0.021 & 0.020 & 0.022 & 0.021 & 0.021 & 0.018 \\
\hline $\operatorname{CQS} Q_{9}$ & 77 & 75 & 80 & 79 & 81 & 78 & 80 & 79 \\
\hline $\operatorname{CQS} Q_{g}$ & 95 & 96 & 94 & 95 & 94 & 94 & 94 & 93 \\
\hline $\operatorname{CQS} Q_{a}$ & 62 & 63 & 65 & 64 & 65 & 63 & 63 & 63 \\
\hline
\end{tabular}




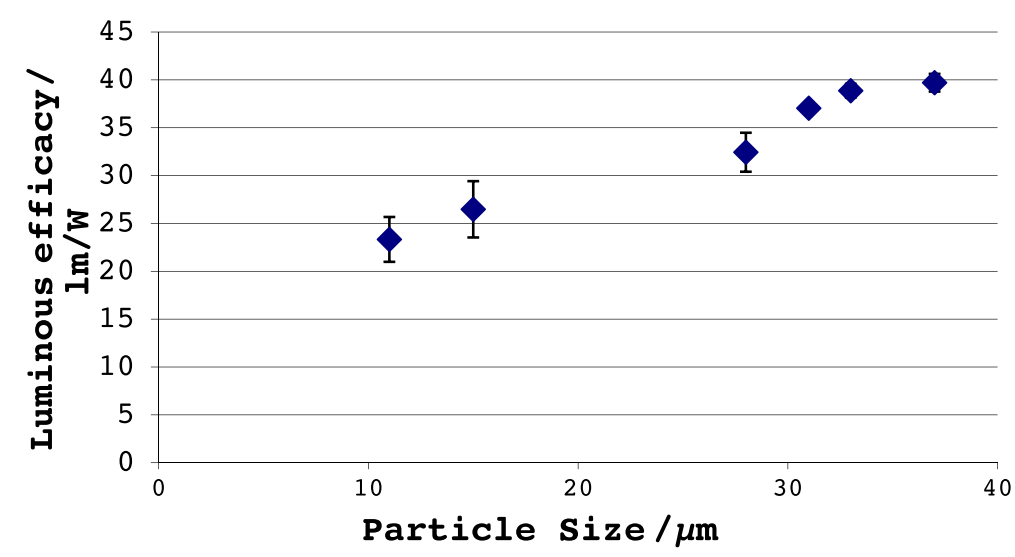

Figure 4 Measured luminous efficacy of the sample PC-LEDs as a function of YAG phosphor particle size.

The difference between the simulated and measured emission spectra represented by the dotted line in Figure 5 enables one to identify at which wavelength discrepancies of simulation occur. Simulated and measured phosphor down conversion as well as the emission around $480 \mathrm{~nm}$ at the junction point in the spectrum between blue emission and phosphor exhibit a good fit: simulated and experimental curves overlap and the difference is small. The simulation differs from the measurements at and around the position of the blue peak. The spectral position of the blue peak wavelength itself is well predicted by the simulation. Differences arise concerning the shape of the blue emission peak. Simulations of the blue LED chip without phosphor perfectly reproduced the blue emission peak but simulations did not match any more when the phosphor was introduced into the program. The mismatch can be ascribed to the phosphor itself. The measured absorption data of the phosphor we implemented in the simulation as an input parameter may not have been appropriate: they might have been too high in the wavelength interval of the blue emission.

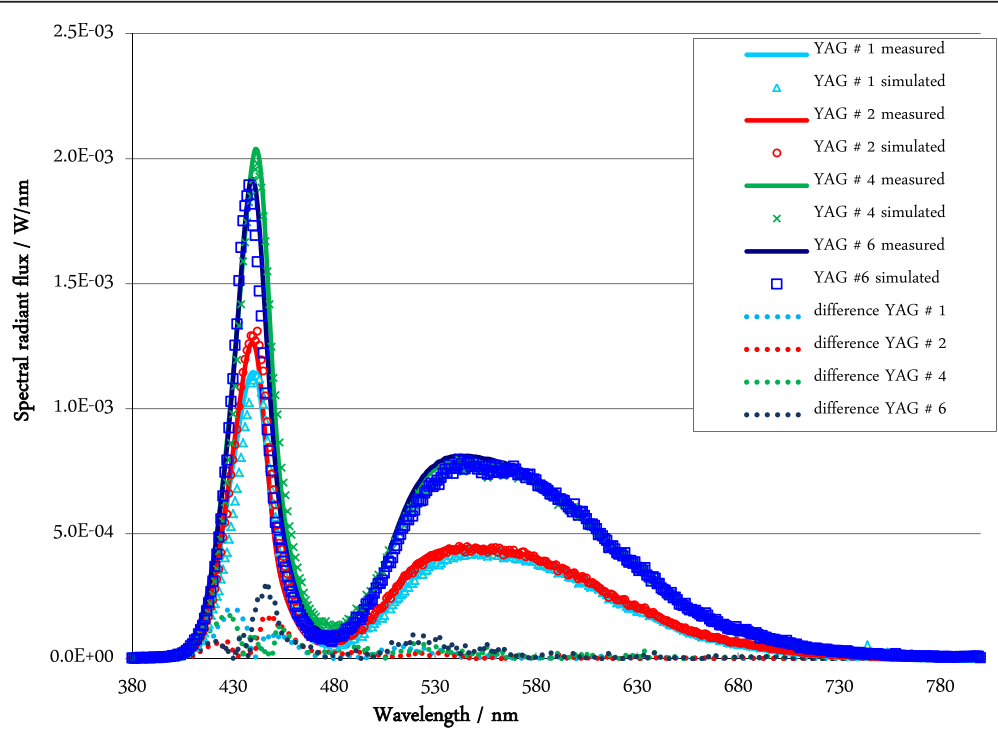

Figure 5 Comparison of simulated and experimental emission spectra for the sample YAG PC-LEDs. 
Turning back to Table 1, there are different ways to evaluate the difference between simulated and measured LED emission spectra. The extent of the error can be evaluated by the emission intensity difference for each wavelength (see Figure 5). Another way to evaluate this error is the computing of a standard measure widely used in lighting engineering which characterizes the perceived quality of white tones i.e. whether the white tone of the PC-LED can be considered as an acceptable or preferred white tone (e.g. without any disturbing greenish shade) when it is assessed visually be the human user [10]. This measure is the white tone chromaticity difference $\Delta u^{\prime} v_{\text {wtq }}^{\prime}$ (the index "wtq" stands for white tone quality) between the chromaticity point of the PC-LED and its so-called reference light source in the CIE $u^{\prime}, v^{\prime}$ chromaticity diagram. The reference light source is a phase of daylight above $5000 \mathrm{~K}$ CCT or a blackbody radiator below $5000 \mathrm{~K}$. The reference light source has the same CCT as the PC-LED. These $\Delta u^{\prime} v^{\prime}{ }_{\text {wtq }}$ values are listed in Table 1.

Because of the not complete matching of the simulated and measured spectral power distributions, the two correlated color temperature (CCT) values do not match. Such differences $(\triangle \mathrm{CCT}=200 \mathrm{~K}-500 \mathrm{~K})$ are visually well noticeable. The general color rendering property of the PC-LEDs represented by the value of the CIE color rendering index (CIE CRI $R_{\mathrm{a}}$ ) exhibits quite similar values for simulation and measurement. All these values (in the range $R_{\mathrm{a}}=71-76$ ) represent only a moderate color rendering property which are, in general, not suitable for general indoor lighting. $R_{9}$ values of measurement and simulation are also similar in the sense that all of them $\left(R_{9}=-3\right.$ to 26) represent visually unacceptable (bad) color rendering for red object colors. The reason of the $R_{9}$ differences is that the simulation does not agree exactly with the measurement in the spectral range between $500 \mathrm{~nm}$ and $560 \mathrm{~nm}$.

The calculated measure of the visual quality of the white tone represented by the value $\Delta u^{\prime} v^{\prime}{ }_{\text {wtq }}$ is very similar for both cases (measured and simulated). Although white tone differences in the range $\Delta u^{\prime} v^{\prime}{ }_{\text {wtq }}=0.001-0.003$ is visually noticeable, this accuracy of the simulation is still very usable to be able to design a phosphor mixture of an intended white tone. Luminous flux differences are considerable, up to $15 \%$. But as the tendency of the influence of phosphor particle size is well reproduced by simulation, the simulation method presented here is able to show the right way for a comprehensive PC-LED light source design (see Figure 1) including all technological and visual aspects.

The values of the CQS metric [11] represent either the combined color rendering and color preference property of the light source $\left(Q_{\mathrm{a}}\right.$ is a general index and $Q_{9}$ characterizes the visually important red colors) or a measure of color gamut, $Q_{\mathrm{g}}$, the so-called relative gamut area. The concept of color gamut means the extent of the set of all possible object colors that appear under the current light source (some light sources tend to suppress saturated object colors while other light sources are able to accentuate saturated object colors). For all CQS measures, there was a good agreement between measurement and simulation.

\section{LuAG}

Another phosphor chemical composition ( $\mathrm{LuAG}, \mathrm{Lu}_{3} \mathrm{Al}_{5} \mathrm{O}_{12}$ :Ce) was also investigated. It was activated by Cerium. Samples with two different activator concentrations (LuAG 1 with $2.7 \%$ and LuAG 2 with $0.63 \%$ ) were tested. The same physical parameter, phosphor particle size, was also examined. Each batch of the LuAG phosphor was sieved in order to 


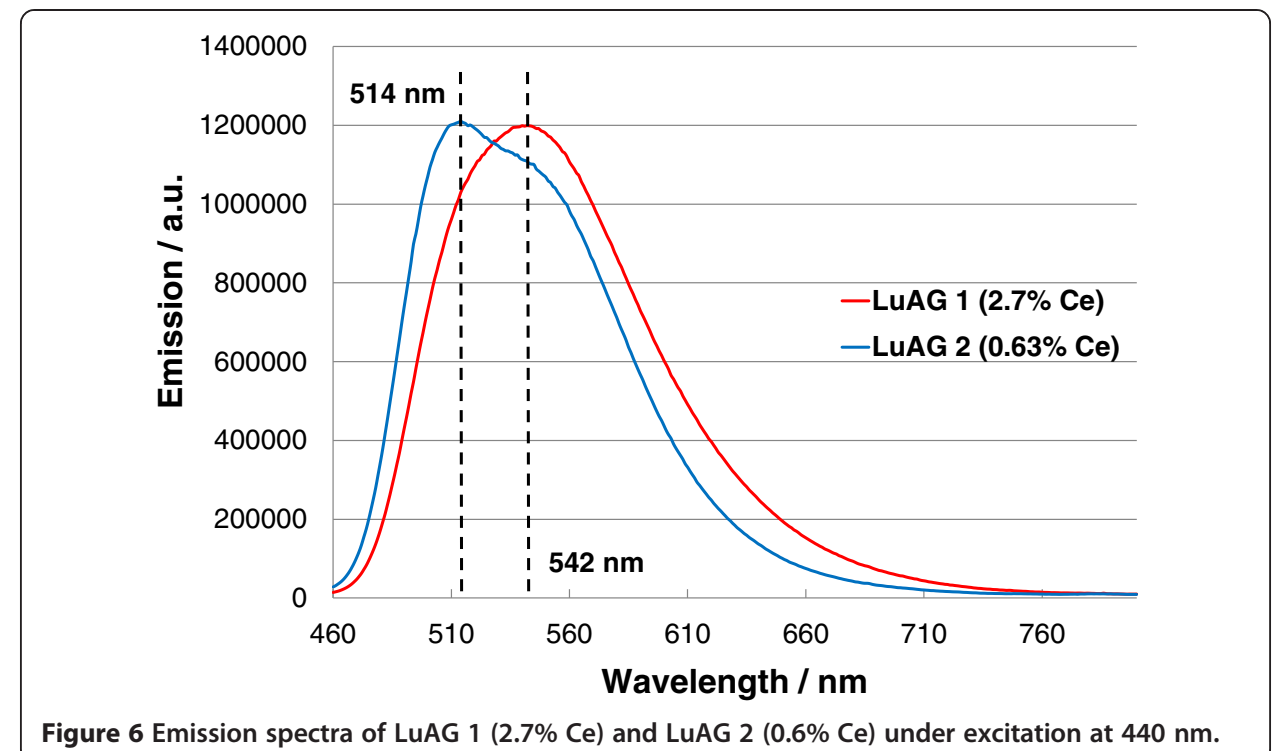

produce LuAG fractions of narrow particle size distribution (PSD) with ratios $d_{90} / d_{10}$ from 1.4 to 1.8. Emission and absorption spectra of LuAG 1 and 2 are presented in Figures 6 and 7. LuAG 1 exhibits an emission peak maximum at 514 nm and LuAG 2 at $542 \mathrm{~nm}$. Both LuAG absorb at $450 \mathrm{~nm}$ in the visible range which suits the application with blue LED. Similar trend is measured by varying the phosphor particle sizes for YAG and LuAG. Increasing the phosphor particle size enhances emission and absorption intensities. The influence of two technological parameters, Cerium dopant concentration and phosphor particle size on the target parameters of the PC-LEDs' light quality was investigated. We made our sample PC-LEDs with only LuAG. Therefore, these sample PC-LED light sources generated green light. So these PC-LEDs could not reach any white point because a red or red-orange phosphor component was missing. Such colored PC-LEDs alone are not suitable for general lighting (they can be suitable for certain unusual accent

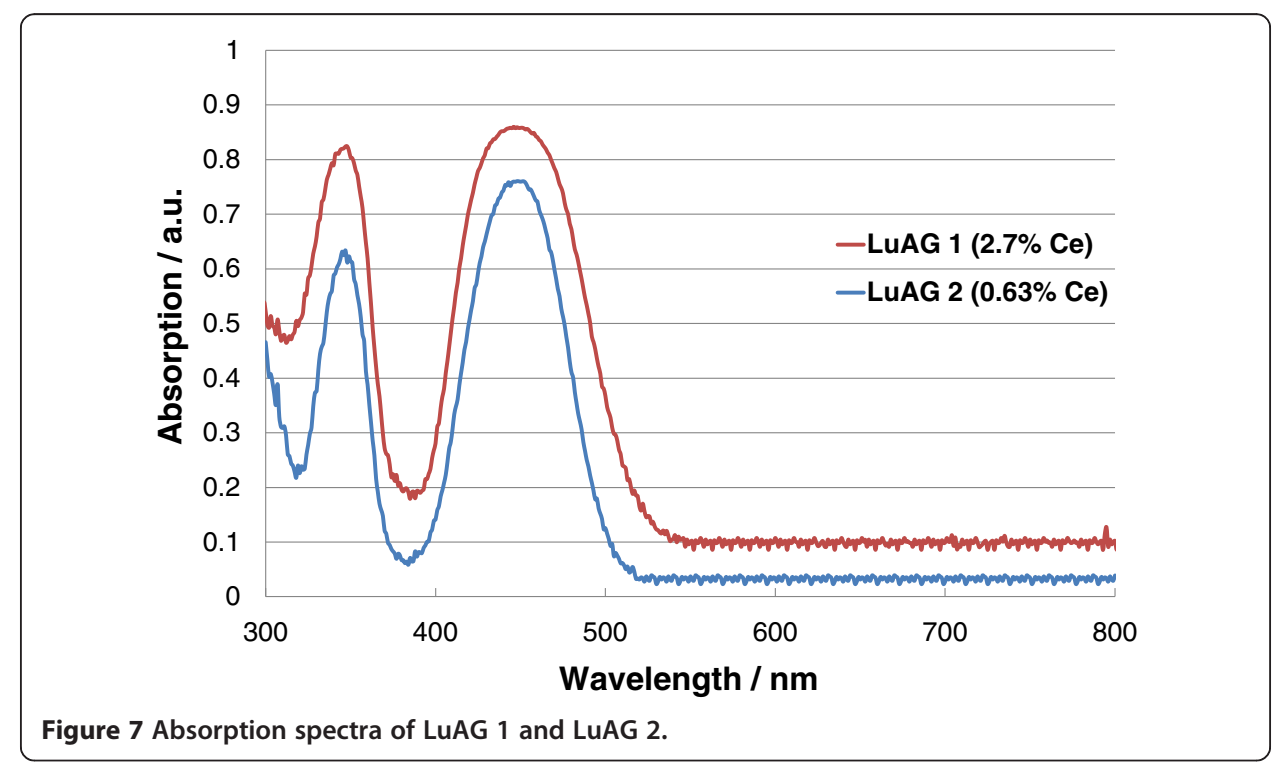


lighting applications). Thus the criteria describing the color quality of white light (color rendering, color gamut, visual white tone quality, color preference) are not described in this section.

Several sample PC-LEDs of similar chromaticities $u^{\prime}=0.1722 \pm 0.0008$ and $v^{\prime}=0.4430 \pm$ 0.0011 for LuAG \#1 and $u^{\prime}=0.1562 \pm 0.0008$ and $v^{\prime}=0.4503 \pm 0.0016$ for LuAG \#2 were built. These chromaticity points were chosen in order to be able to reach cool white LEDs of at a usable color rendering level at a later stage, in combination with a red-orange phosphor, see Section A phosphor system.

Spectral radiant flux distributions for the sieved fractions LuAG \#2 (\#2 as an example) are shown in Figure 8. The median particle sizes $d_{50}$ of the corresponding sieved fractions are specified in the caption.

As can be seen from Figure 8, because of the constant chromaticity, the relative shape of these spectral emission curves is independent of phosphor particle size. The proportion of the blue and green emission components remains constant and phosphor particle size plays a role in the absolute emission intensity only. Luminous efficacy as a function of phosphor particle size is plotted in Figure 9 for both LuAG \#1 and LuAG \#2.

Figure 9 shows that luminous efficacy increases with increasing particle size. The reason is the same as for the YAG phosphor (see Section YAG): small particles exhibit more backscattering and the backscattered radiation is sent back and absorbed by the blue LED chip. Moreover, smaller particle surfaces are also more seriously affected by material defects in their microstructure. Latter effect is attributed to a stop in crystal formation. This effect results in increased reflectance for the case of smaller particles. Therefore, the luminous efficacy of the PC-LED decreases.

It can also be seen from Figure 9 that LuAG \#2 (with $0.63 \% \mathrm{Ce}$ ) exhibits higher luminous efficacies than LuAG \#1 (with $2.7 \% \mathrm{Ce}$ ), at least for smaller particle sizes. Chen reported the enhancement of crystal splitting by increasing activator concentration [12]. $\mathrm{Ce}^{3+}$ relaxes by electron-phonon interaction to lower energy sites which leads to a red-shift emission and, consequently, a lower energy [13,14].

Simulations to reproduce the physically measured LuAG emission spectra were also carried out and the performance of our simulation method to point out the influence

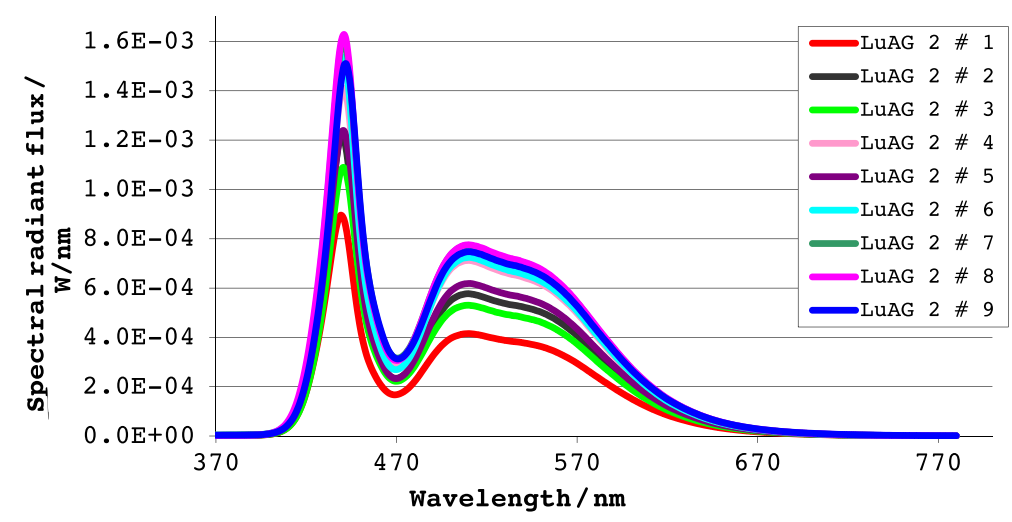

Figure 8 PC-LED emission intensity for LUAG \#2 for the following median phosphor particle sizes $d_{50}$ (in brackets): LuAG \#2\# $1(4.4 \mu \mathrm{m})$, LuAG \#2\# $2(8.5 \mu \mathrm{m})$, LuAG \#2\# $3(17.6 \mu \mathrm{m})$, LuAG \#2\# 4 $(22 \mu \mathrm{m})$, LuAG \#2\# $5(26.9 \mu \mathrm{m})$, LuAG \#2\# $6(31.5 \mu \mathrm{m})$, LuAG \#2\# $7(37 \mu \mathrm{m})$, LuAG \#2\# $8(47 \mu \mathrm{m})$, LuAG \#2\# $9(70 \mu \mathrm{m})$. 


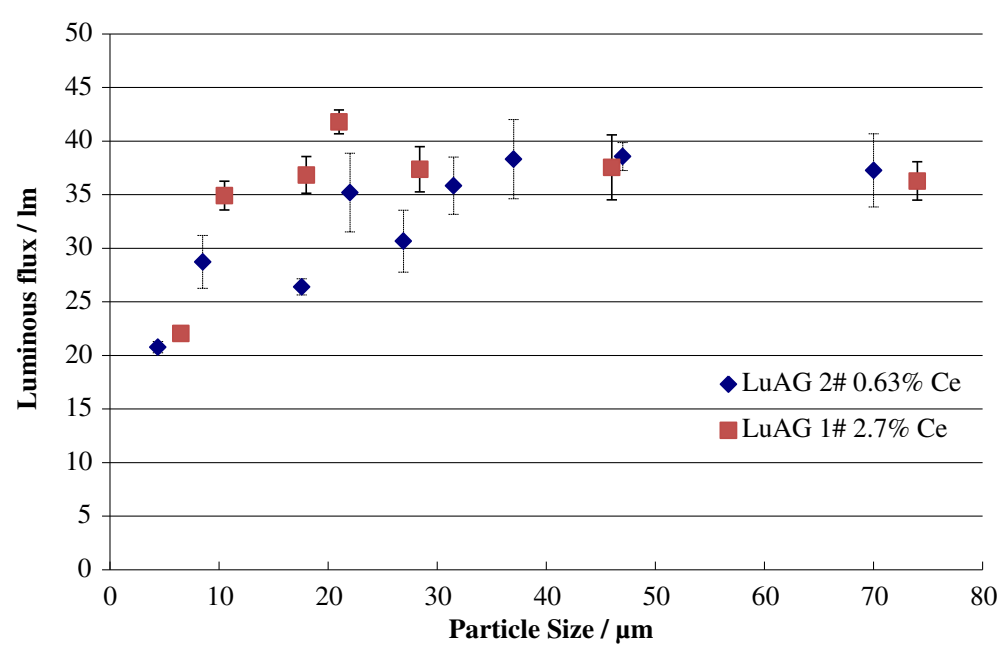

Figure 9 Luminous efficacy as a function of phosphor particle size for LuAG \#1 and LuAG \#2.

of particle size was tested. Simulated and measured results for the sieved fractions extracted from LuAG \#1 are shown in Figure 10. The difference between the measured and the simulated spectral radiant flux distributions are plotted in the same graph.

The dotted line shows the difference between the simulated and the measured PCLED emission spectra. Simulated and measured PC-LED spectra exhibit a good match from $520 \mathrm{~nm}$ on i.e. in the main spectral range of the phosphor part of the PC-LED's emission curve. It should be noted that the phosphor's photoluminescence data given as an input parameter in the software are of great influence and may enable a consistent simulation of down conversion emission. It should be emphasized at this point that the success or failure of simulation does not only depend on the software itself (LightTools ${ }^{\circ}$ in the case of the present paper) but much on the way how it is used by the software user, especially how carefully the input data are prepared. The software itself is a good tool but

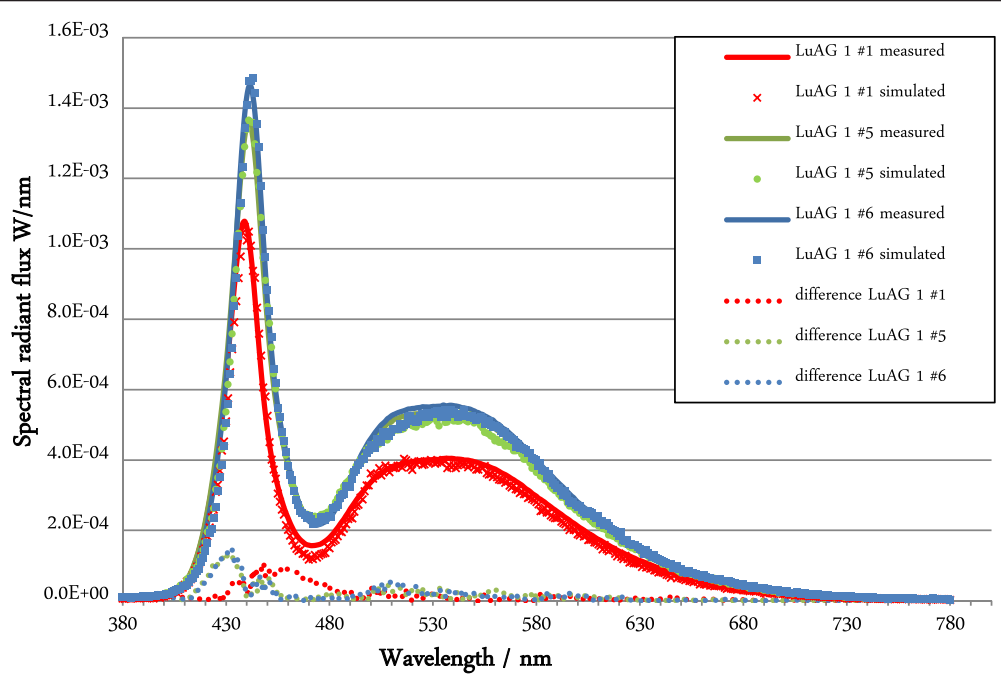

Figure 10 Spectral radiant flux of the different sieved fractions for LuAG \# 1 (particle sizes can be seen in the brackets of the Caption of Figure 8): Simulation, measurement and difference between simulation and measurement. 
it is up to the user to provide a good input for the software (see also below). Matching problems of the spectral radiant flux distributions are situated at about $430 \mathrm{~nm}$ and also at the transition point between the blue pump LED and the green phosphor at $470 \mathrm{~nm}$.

At this spectral transition point, the simulated emission is too low. This is probably caused by an erroneous consideration of phosphor absorption characteristics in our measurement. We measured the photoluminescence properties of the phosphor as the input parameter of the simulation software in reflection mode on the surface of the phosphor sample. However, multiple reflections might possibly have occurred and changed the shape of the spectral absorption curve. A better way of absorption measurements would have been to use transmission mode to eliminate this possible error source. But this option was not possible due to the lack of such laboratory equipment in our research.

Radiant flux differences and chromaticity differences between measurement and simulation can be seen in Table 2. As mentioned above, these LuAG PC-LEDs are colored LEDs without any white point and with no corresponding reference light source. Therefore, the chromaticity difference $\Delta u^{\prime} v^{\prime}$ is computed here in a different sense from Section YAG. Here, it is computed between the simulated and measured versions of the chromaticity points of the LuAG emission spectra and it is designated by $\Delta u^{\prime} v_{\mathrm{ms}}^{\prime}$.

As can be seen from Table 2, measured radiant flux and simulated radiant flux agree up to about 7\%. The difference in the shape of the spectral emission curves implies discrepancies in the chromaticity point of the LuAG PC-LEDs up to $\Delta u^{\prime} v^{\prime}=0.0047$ (see the fourth column of Table 2) which is a visually well noticeable difference. In addition, a spectral difference measure designated by $D$ was defined here as the sum of the spectral radiant flux differences between simulation and measurement at each wavelength. The computed $D$ values demonstrate that the agreement between the simulated and the measured emission spectra varies among the different PC-LEDs (\#1-\#7) considerably.

As seen above, despite these differences, our simulation provided usable results concerning radiant flux. Accurate chromaticity simulation, however, remains an important challenge as the chromaticity point depends on the relative shape of the emission spectrum (measured or simulated) strongly. A spectral mismatch in the $440 \mathrm{~nm}-470 \mathrm{~nm}$ range is decisive for the chromaticity match between simulation and measurement. As for the YAG simulations, the emission of the blue LED could not be simulated in a satisfying way. Phosphor absorption properties are suspected to cause this difference in the

Table 2 Radiant flux and chromaticity differences between measurement and simulation

\begin{tabular}{lcccc}
\hline & \multicolumn{2}{c}{ Radiant flux/W } & $\Delta \boldsymbol{u}^{\prime} \boldsymbol{v}^{\prime}$ & $\boldsymbol{D}$ \\
\cline { 2 - 3 } & Simulated & Measured & & \\
\hline LUAG 1 \#1 & $7.42 \mathrm{E}-02$ & $7.64 \mathrm{E}-02$ & 0.0036 & 0.005 \\
LUAG 1 \#2 & $1.12 \mathrm{E}-01$ & $1.16 \mathrm{E}-01$ & 0.0047 & 0.005 \\
LUAG 1 \#3 & $1.06 \mathrm{E}-01$ & $1.22 \mathrm{E}-01$ & 0.0006 & 0.017 \\
LUAG 1 \#4 & $1.28 \mathrm{E}-01$ & $1.37 \mathrm{E}-01$ & 0.0015 & 0.011 \\
LUAG 1 \#5 & $9.98 \mathrm{E}-02$ & $1.03 \mathrm{E}-01$ & 0.0016 & 0.033 \\
LUAG 1 \#6 & $1.02 \mathrm{E}-01$ & $1.06 \mathrm{E}-01$ & 0.0013 & 0.006 \\
LuAG 1 \#7 & $1.08 \mathrm{E}-01$ & $1.16 \mathrm{E}-01$ & 0.0032 & 0.010 \\
\hline
\end{tabular}

The quantity $D$ is defined as the sum of the spectral radiant flux differences between simulation and measurement at each wavelength. 
simulation of the blue part of the PC-LED's emission spectrum. The tendency of the influence of phosphor particle size could be well simulated.

It should be mentioned that the LightTools software is based on the theoretical assumption of spherical particles and this does not correspond to reality. Two other factors, the heat lost at the chip and the reflectance of the metal ring which contains the phosphor, are approximated only roughly. These approximations might also have caused the spectral deviations shown above.

\section{A phosphor system}

At the next stage of our research, a system of four phosphors was considered to produce white PC-LEDs that emit white light which may be suitable for general interior lighting purposes. This suitability means the ability to provide a white tone of good visual quality (with $\Delta u^{\prime} v_{\text {wtq }}^{\prime} \leq 0.002$ [15]) and a good general color rendering index (with $R \mathrm{a} \geq 86$ [16]). To try to do so, two green phosphors and two red-orange phosphors were used: LuAG \#2 (see Section LuAG) with a broad spectral emission curve (green 1, G1), an orthosilicate (green 2, G2) [Ba, Sr, Ca $]_{2} \mathrm{SiO}_{4}: \mathrm{Eu}$, a red-orange oxyorthosilicate (red 1, R1) [Sr, $\left.\mathrm{Ba}\right] \mathrm{Si}_{3} \mathrm{O}_{5}$ : $\mathrm{Eu}$ and a red-orange nitride phosphor (red 2, R2). Efforts were taken so that the PC-LEDs with one green and one red phosphor differed only in the type of their phosphors: they were built by using the same blue LED chip, the same driving currents and to exhibit similar CCTs ranging from cool white to warm white. Emission and absorption spectra of the four phosphors are represented in Figures 11 and 12.

The measured spectral radiant flux distributions of PC-LEDs (with the following phosphor combinations: G1/R1, G1/R2, G2/R1 and G2/R2) constructed from the above mentioned four types of phosphor are illustrated in Figure 13 for the investigated range of CCT values.

As can be seen from Figure 13, only one phosphor combination G2/R1 at $3100 \mathrm{~K}$, $4300 \mathrm{~K}$ and $5200 \mathrm{~K}$ is able to approximate $\left(R_{\mathrm{a}}=85\right)$ the $R_{\mathrm{a}} \geq 87$ criterion level above which the general color rendering can be considered good [15]. This is due to the fact that the two red-orange phosphors (R1, R2) we used do not emit enough in the red - deep red

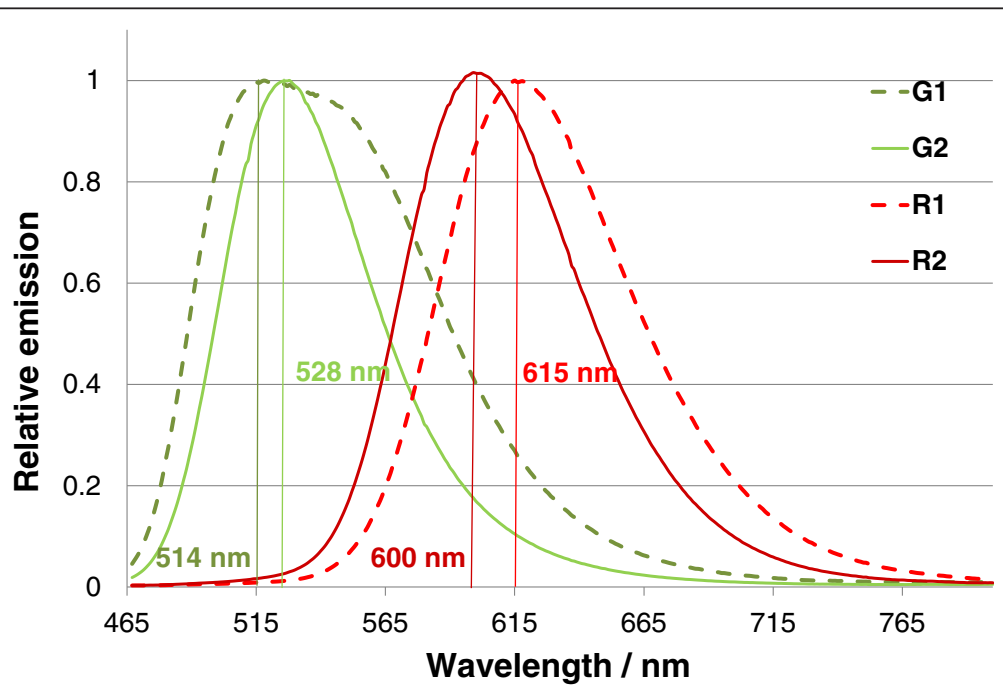

Figure 11 Emission spectra of G1, G2, R1 and R2 phosphors under excitation at $400 \mathrm{~nm}$. 


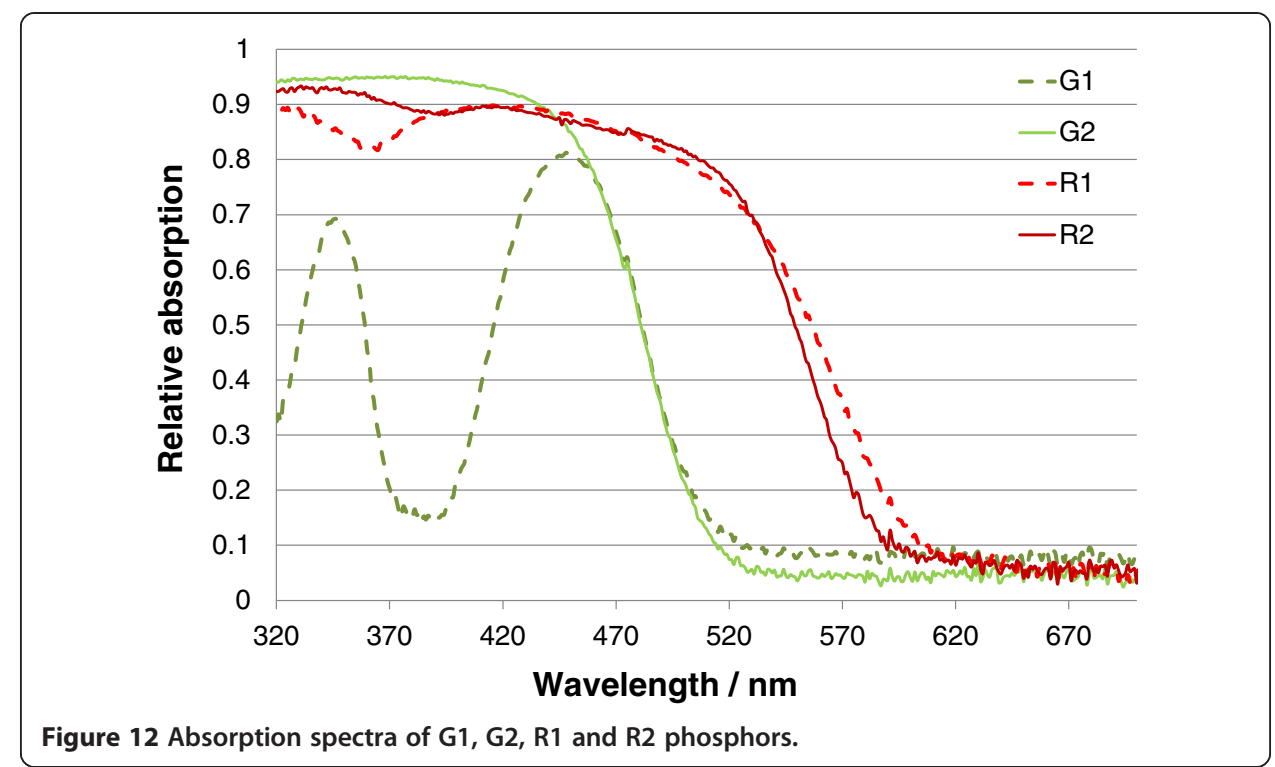

spectral range $(610 \mathrm{~nm}-660 \mathrm{~nm})$ hence they do not provide enough red spectral content to illuminate important reddish objects. The use of red - deep red emitting phosphors shall be considered in the future to obtain interior PC-LED light sources of high color quality. Note that, for a more comprehensive, up-to-date analysis of the color rendering color quality issue, not only the general color rendering index but also a set of object specific color rendering indices shall be considered [15] but this is out of the scope of this article. Also note that the CIE CRI color rendering index computation method is currently being modernized in the CIE. A new color rendering index has been developed [16] but

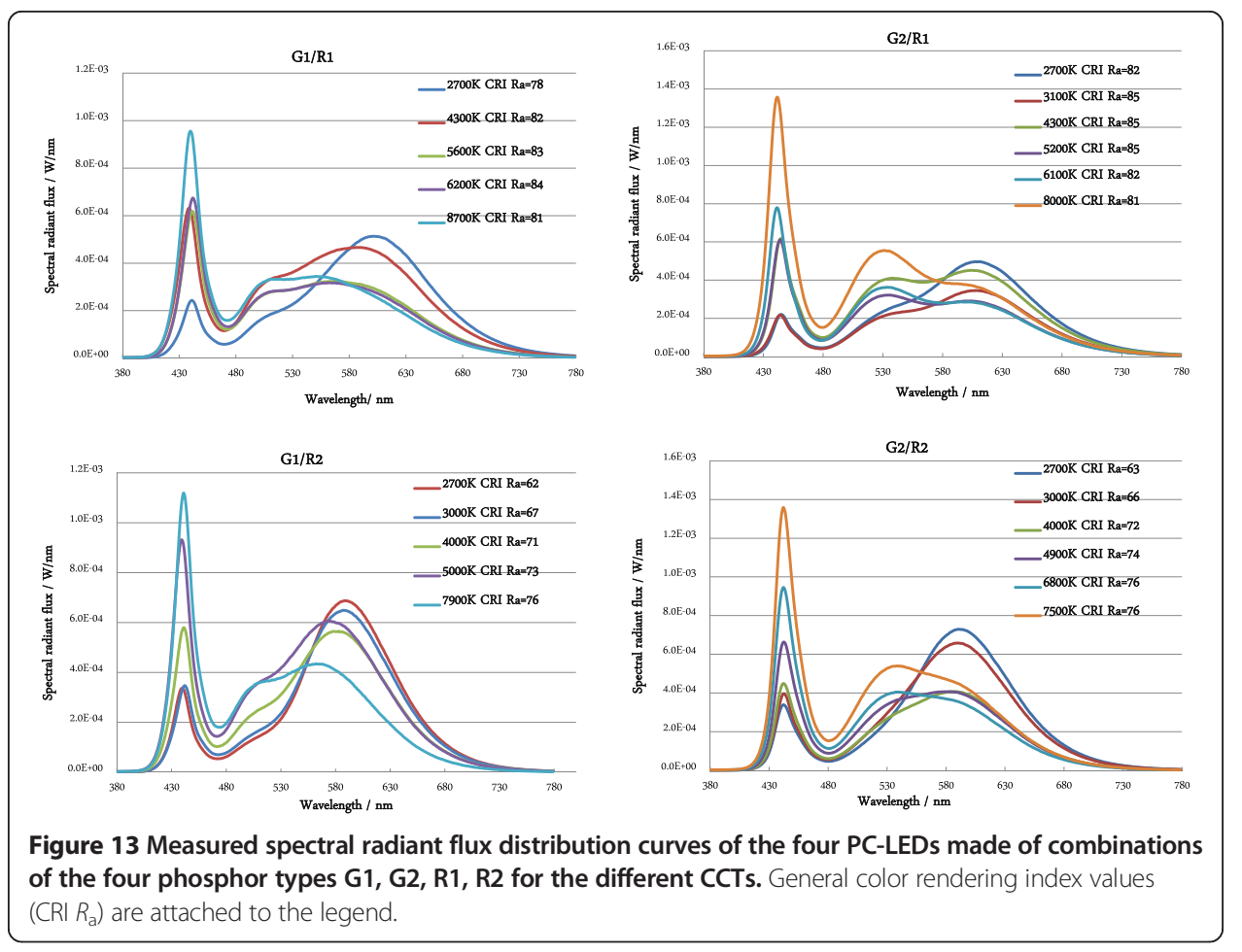


as it has not been officially endorsed by the CIE at the time of writing, it is not dealt with in this paper.

Warm white LEDs ( $2700 \mathrm{~K}, 3000 \mathrm{~K}$ ) were obtained by adding a high amount of redorange phosphor to the mixture. This fact leads to the higher red-orange peaks. The analysis of the photoluminescent properties of the phosphors (used as input data for the simulation) revealed that the green emission overlapped with the red-orange phosphor's excitation and absorption ranges in the spectrum (see Figures 11 and 12). Due to this interaction of the green and red-orange phosphor components, the amount of green phosphor still had to be high in order to achieve the right correlated color temperature (CCT) and a visually acceptable white tone without any disturbing color shade (e.g. a greenish tone which is not acceptable when the PC-LED is intended to be used for general lighting). Of course, both phosphors required excitation from the blue pump LED. Therefore, the warm white PC-LEDs exhibited a lower blue emission. In turn, when white PC-LEDs get a higher CCT (cool white, e.g. $6000 \mathrm{~K}$ ) then less red-orange phosphor is necessary but there must be more green emission and more blue emission.

The experimentally obtained spectral emission curves of Figure 13 were simulated again with LightTools ${ }^{\circ}$. Figure 14 compares the experimental and the simulated spectral emission curves for the system G1/R1 as an example. The difference between the two spectral emission curves is plotted again with a dot line.

As can be seen from Figure 14, an increasing amount of green phosphor reduces the amount of blue emission because the blue rays are used to excite the green phosphor. The red-orange phosphor also absorbs the blue emission but it absorbs the green emission, as well. To increase red-orange emission intensity by keeping green emission intensity at the same level, red-orange phosphor concentration must be increased but green phosphor concentration must also be increased. This fact considerably decreases blue light output. The point is that this behavior could be simulated successfully, as can be seen from the comparison of the measured and simulated spectral emission characteristics of Figure 14. For this, here again, appropriate phosphor input photoluminescent data

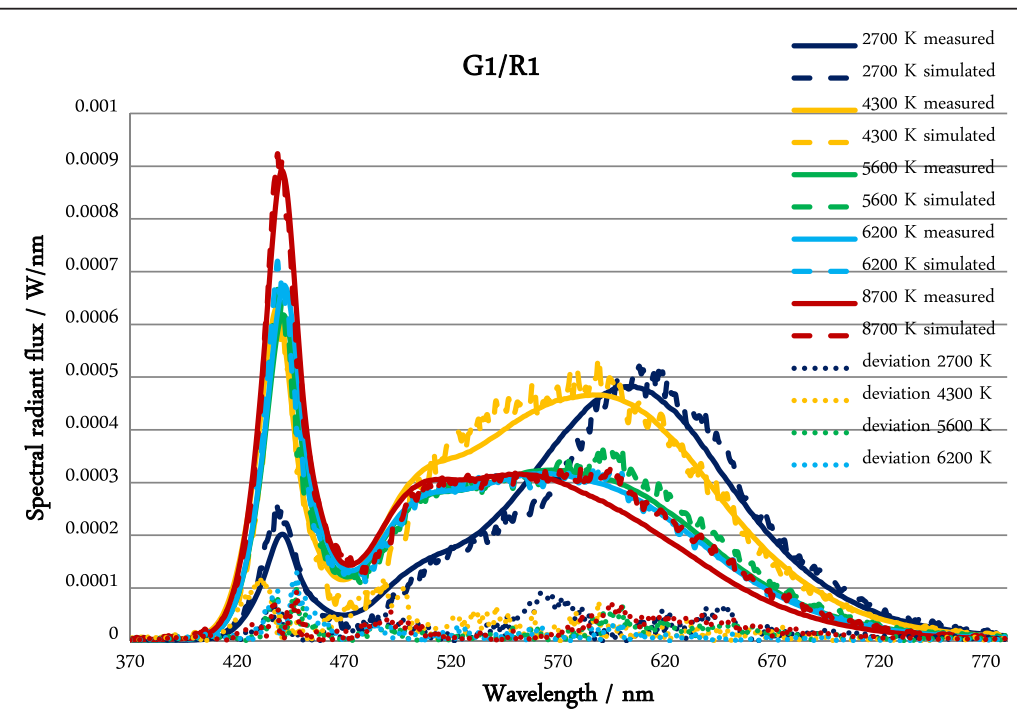

Figure 14 Spectral radiant flux of the G1/R1 PC-LEDs for several CCTs: Simulation, measurement and difference between simulation and measurement. 
had to be provided for the simulation software. A similar fit between the simulated and experimental spectral emission curves was obtained for the other phosphor mixtures (G1/ R2, G2/R1, G2/R2) as well. Proportions among the peak blue, peak green and peak redorange spectral radiant flux values agreed well between the simulations and the measurements across the different CCTs.

To point out the effect of the differences between measurement and simulation on the human visual system (i.e. for the human user of the PC-LED light source), radiometric, photometric and colorimetric descriptor quantities were calculated for the above spectral emission curves. The differences of luminous flux, color rendering index (CRI) and CCT between the measured and simulated spectra were computed, see Table 3. The distance between the chromaticity points of the measured and simulated PC-LEDs ( $\left.\Delta u^{\prime} v_{\mathrm{ms}}^{\prime}\right)$ and the distance between the measured (or simulated) chromaticity points of the PC-LED and its reference light source (the measure of visual white tone quality, $\Delta u^{\prime} v_{\text {wtq,m }}^{\prime}$ or $\Delta u^{\prime} v_{\text {wtq, }}^{\prime}$ ) were also computed, see Table 3. Relative and absolute radiant flux differences between simulation and measurement are shown in the last columns of Table 3.

As can be seen from Table 3, measured and simulated luminous flux and CRI values agree reasonably. The measured white tone characteristics $\left(\Delta u^{\prime} v_{\text {wtqmeas }}^{\prime}\right)$ remain less than $5 \cdot 10^{-3}$ (mean: $2,1 \cdot 10^{-3}$ ) which confirms that the sample PC-LEDs we built yielded reasonable white tones. Nevertheless, some white tone discrepancies between simulation and measurements exist. The measure of white tone quality of the simulated white PC-LED spectra $\left(\Delta u^{\prime} v_{\text {wtq,sim }}^{\prime}\right)$ reached values up to $1.23 \cdot 10^{-2}$ (mean: $5,2 \cdot 10^{-3}$ ). The maximum value $\left(\Delta u^{\prime} v^{\prime}{ }_{\text {wtq,sim }}=1.23 \cdot 10^{-2}\right)$ corresponds to a visually not acceptable white tone. Simulated chromaticity points also deviate from measured ones (see the $\Delta u^{\prime} v_{m s}^{\prime}$ values). As a consequence, measured and simulated CCT values differ, as well and this difference is visually well noticeable.

All these deviations result from the differences of the measured and simulated spectral power distributions. In Figure 14, it is possible to identify at which wavelengths the spectral power differences are the highest (for the example G1/R1). Absolute and relative radiant flux differences between the simulated and measured emission spectra $\left(\Delta \Phi_{\mathrm{e}}\right)$ vary from $1 \%$ to $12 \%$ (see Table 3). These differences are ascribed to the simulated emission discrepancies occurring around the blue peak emission (420 nm - $440 \mathrm{~nm}$ ), in the spectral transition range between the blue LED and the green phosphor emission $(460 \mathrm{~nm}-500 \mathrm{~nm})$ and in the transition between the green and red-orange phosphor emissions (550 nm - $600 \mathrm{~nm}$ ).

The reason of the spectral mismatch between simulation and measurement can be attributed to the discrepancies of phosphor absorption data (our input parameter for the simulation program). The deviation around the blue emission peak and at the transition range about $470 \mathrm{~nm}$ occurs due to similar reasons as discussed for YAG and LuAG in the previous Sections YAG and LuAg. The PC-LED configuration considered in this section is represented by a complex system of two phosphors in which the red-orange phosphor's photoluminescent properties [13] influence the emission spectra of the green phosphors. Our absorption measurements on the phosphors to provide the input parameter for the simulation program influence the multiple phosphor interactions within these PC-LED made of the mixture of two phosphor components very strongly. In this case, down converting processes are influenced by the interaction of both phosphors resulting in the difficulty to simulate these emission spectra. 
Table 3 Differences of radiant flux $\left(\Delta \Phi_{\mathrm{e}}\right)$, luminous flux $\left(\Delta \Phi_{\mathrm{v}}\right)$, correlated color temperature $(\Delta C C T)$, chromaticity $\left(\Delta u^{\prime} v^{\prime}\right)$ and general color rendering index $\left(\Delta R_{\mathrm{a}}\right)$ between the simulated and the measured spectral emission curves for the four phosphor mixtures

\begin{tabular}{|c|c|c|c|c|c|c|c|c|c|}
\hline \multicolumn{10}{|l|}{ G1/R1 } \\
\hline$\overline{\mathrm{CCT} / \mathrm{K}}$ & $\Delta \Phi_{\mathrm{v}} / \mathrm{Im}$ & $C R I, R_{a, \text { meas }}$ & $\Delta \mathrm{CRI} R \mathrm{Ra}$ & $\Delta \mathrm{CCT} / \mathrm{K}$ & $\Delta u^{\prime} v^{\prime}$ wtq & $\Delta u^{\prime} v^{\prime}{ }_{m}$ & $\Delta u^{\prime} v^{\prime}{ }_{s}$ & $\Delta \Phi_{\mathrm{e}} / \%$ & $\Delta \Phi_{\mathrm{e}} / \mathrm{W}$ \\
\hline 2700 & 2 & 78 & 4 & 238 & 1.39E-02 & $7.31 \mathrm{E}-04$ & $1.02 \mathrm{E}-02$ & 0.4 & 0.0083 \\
\hline 4300 & 1 & 82 & 7 & 182 & 1.09E-02 & 4.12E-04 & 8.90E-03 & 3.6 & 0.0094 \\
\hline 5600 & 1 & 83 & 1 & 519 & 7.78E-03 & 3.43E-03 & $8.44 \mathrm{E}-03$ & 3.6 & 0.0058 \\
\hline 6200 & 0.1 & 84 & 1 & 260 & 4.30E-03 & $4.72 \mathrm{E}-03$ & $3.13 \mathrm{E}-03$ & 0.5 & 0.0044 \\
\hline 8700 & 0.9 & 81 & 3 & 1523 & $1.23 \mathrm{E}-02$ & 2.91E-03 & $1.23 \mathrm{E}-02$ & 4.3 & 0.0074 \\
\hline \multicolumn{10}{|l|}{ G1/R2 } \\
\hline$\overline{\mathrm{CCT} / \mathrm{K}}$ & $\Delta \Phi_{\mathrm{v}} / \mathrm{Im}$ & $C R I, R_{a, \text { meas }}$ & $\Delta \mathrm{CRI} R \mathrm{Ra}$ & $\Delta \mathrm{CCT} / \mathrm{K}$ & $\Delta$ u'v' $^{\prime}$ wtq & $\Delta u^{\prime} v^{\prime}{ }_{m}$ & $\Delta u^{\prime} v^{\prime}{ }_{s}$ & $\Delta \Phi_{\mathrm{e}} / \%$ & $\Delta \Phi_{\mathrm{e}} / \mathrm{W}$ \\
\hline 2700 & 4 & 62 & 1 & 257 & 1.43E-02 & 1.33E-03 & $1.08 \mathrm{E}-02$ & 12.2 & 0.0102 \\
\hline 3000 & 2 & 67 & 0 & 208 & 8.03E-03 & 1.46E-03 & 4.51E-03 & 6.4 & 0.0058 \\
\hline 4000 & 1 & 71 & 1 & 175 & 4.55E-03 & 8.85E-04 & $2.22 \mathrm{E}-03$ & 2.1 & 0.0055 \\
\hline 5000 & 1.9 & 73 & 3 & 198 & $6.55 \mathrm{E}-03$ & $3.85 \mathrm{E}-03$ & $9.01 \mathrm{E}-05$ & 3.7 & 0.0069 \\
\hline 7900 & 0.9 & 76 & 1 & 536 & 4.49E-03 & $2.34 \mathrm{E}-03$ & $3.48 \mathrm{E}-03$ & 3.1 & 0.0052 \\
\hline \multicolumn{10}{|l|}{ G2/R1 } \\
\hline$\overline{\mathrm{CCT} / \mathrm{K}}$ & $\Delta \Phi_{\mathrm{v}} / \mathrm{lm}$ & $C R I, R_{a, \text { meas }}$ & $\Delta \mathrm{CRI} R \mathrm{Ra}$ & $\Delta \mathrm{CCT} / \mathrm{K}$ & $\Delta u^{\prime} v^{\prime}{ }_{\text {wtq }}$ & $\Delta u^{\prime} v^{\prime}{ }_{m}$ & $\Delta u^{\prime} v^{\prime}{ }_{s}$ & $\Delta \Phi_{\mathrm{e}} / \%$ & $\Delta \Phi_{\mathrm{e}} / \mathrm{W}$ \\
\hline 2700 & 0 & 82 & 2 & 50 & $2.18 \mathrm{E}-03$ & $1.72 \mathrm{E}-03$ & $2.29 \mathrm{E}-03$ & 2.5 & 0.0052 \\
\hline 3100 & 0 & 85 & 1 & 71 & $3.72 \mathrm{E}-03$ & 1.15E-03 & $6.55 \mathrm{E}-04$ & 2.2 & 0.0040 \\
\hline 4300 & 1 & 85 & 2 & 23 & 2.92E-03 & $5.86 \mathrm{E}-04$ & $3.66 \mathrm{E}-03$ & 1.9 & 0.0063 \\
\hline 4700 & 0.0 & 85 & 4 & 175 & $1.02 \mathrm{E}-02$ & 4.91E-04 & 8.75E-03 & 3.9 & 0.0053 \\
\hline 5200 & 0.4 & 85 & 3 & 7 & 2.26E-03 & $4.98 \mathrm{E}-03$ & $7.28 \mathrm{E}-03$ & 2.8 & 0.0050 \\
\hline 6100 & 1.0 & 82 & 3 & 295 & $9.84 \mathrm{E}-03$ & $3.41 \mathrm{E}-03$ & $4.04 \mathrm{E}-03$ & 0.0 & 0.0051 \\
\hline 8000 & 0.2 & 81 & 1 & 329 & 3.63E-03 & 2.89E-03 & $1.35 \mathrm{E}-03$ & 2.5 & 0.0053 \\
\hline \multicolumn{10}{|l|}{ G2/R2 } \\
\hline $\mathrm{CCT} / \mathrm{K}$ & $\Delta \Phi_{\mathrm{v}} / \mathrm{Im}$ & $C R I, R_{a \text {,meas }}$ & $\Delta$ CRI Ra & $\Delta \mathrm{CCT} / \mathrm{K}$ & $\Delta$ u'v' $^{\prime}{ }_{\text {wtq }}$ & $\Delta$ u'v $^{\prime}{ }_{\mathrm{m}}$ & $\Delta$ u'v' $^{\prime}{ }_{\mathrm{s}}$ & $\Delta \Phi_{\mathrm{e}} / \%$ & $\Delta \Phi_{\mathrm{e}} / \mathrm{W}$ \\
\hline 2700 & 0 & 63 & 1 & 91 & 6.64E-03 & $9.84 \mathrm{E}-04$ & $5.18 \mathrm{E}-03$ & 3.6 & 0.0077 \\
\hline 3000 & 0 & 66 & 2 & 293 & 1.29E-02 & $1.25 \mathrm{E}-03$ & $1.16 \mathrm{E}-02$ & 4.7 & 0.0101 \\
\hline 4000 & 0 & 72 & 4 & 67 & $6.01 \mathrm{E}-03$ & $1.14 \mathrm{E}-03$ & $5.26 \mathrm{E}-03$ & 3.4 & 0.0061 \\
\hline 4900 & 1.3 & 74 & 4 & 169 & 3.33E-03 & 3.35E-04 & 3.51E-04 & 5.9 & 0.0111 \\
\hline 6800 & 0.3 & 76 & 7 & 35 & $6.21 \mathrm{E}-03$ & $3.82 \mathrm{E}-03$ & $2.23 \mathrm{E}-03$ & 2.5 & 0.0097 \\
\hline 7500 & 0.0 & 76 & 7 & 243 & 7.37E-03 & $3.72 \mathrm{E}-03$ & $2.50 \mathrm{E}-03$ & 4.0 & 0.0122 \\
\hline
\end{tabular}

$\Delta u^{\prime} v_{\text {ms }}^{\prime}$ : distance between the chromaticity points of the measured and simulated PC-LEDs; $\Delta u^{\prime} v_{\text {wtq, }}^{\prime}$ : distance between the chromaticity point of a measured PC-LED spectrum and its reference light source (the measure of visual white tone quality for the measured PC-LED spectrum); $\Delta u^{\prime} v_{\text {wtq, }}^{\prime}$ : the same for the corresponding simulated spectrum; $R_{\mathrm{a}, \mathrm{m}}$ is the CIE general color rendering index computed from the measured spectrum (E-02 means $\cdot 10^{-2}$, etc.).

\section{Conclusion}

In this article, LED light sources using down converting phosphors (phosphor converted LEDs or PC-LEDs) were studied. The influence of the phosphors' chemical, physical and technological properties on the spectral power distributions and the visual lighting quality parameters of the PC-LEDs were investigated by constructing sample PC-LEDs and by simulating them in LightTools. The influence of YAG and LuAG phosphor particle size and activator concentration on the PC-LEDs lighting quality was dealt with. Further sample PC-LEDs with the mixture of two phosphors of a four-phosphor system were built and luminous efficacy and color quality measures were computed. These PC-LED 
properties were strongly influenced by the photoluminescent data of the phosphors as input parameters for the simulation program. Simulation results based on the measured photoluminescent input parameters of the phosphors and the measurement results of the sample PC-LEDs were compared. The simulation method was corroborated to be a usable and important tool to optimize the technological parameters of the PC-LEDs for general lighting to obtain high luminous efficacy and high color quality.

The method presented in this paper is an interdisciplinary and comprehensive method with the following aspects: 1 . photoluminescent properties of the phosphors were measured and provided as input data for LightTools ; 2. sample PC-LEDs were built; 3. their absolute spectral power distributions were measured and simulated based on the input data; 4. lighting quality measures (luminous efficacy, white tone quality, color rendering index, etc.) were computed for both the measured and the simulated spectra; 5 . measured and simulated results were compared and simulation accuracy was determined. It turned out that this simulation method is usable to optimize the visual quality measures of PC-LED light sources for general lighting purposes because the simulation method is able to predict the tendencies of spectral power distribution changes when the technological parameters of the phosphors are changed systematically.

Concerning the analysis of the possible causes of the deviations between measurement and simulation, one important issue is that the simulation is based on the assumption of spherical phosphor particles which does not hold in reality. Nevertheless, the tendencies of the PC-LEDs' lighting properties by varying phosphor size and also with varying activator concentration could be simulated with reasonable accuracy both for YAG and for LuAG, e.g. increasing phosphor particle size resulted in higher luminous efficacy both in measurement and in simulation.

The last section described certain types of green and red-orange phosphor mixtures. The measurement and simulation of these spectral power distributions contribute to the understanding of new phosphor mixtures. Results provided by the simulation strongly depend on the phosphor absorption provided as an input parameter for the simulation software. Simulated luminous flux and radiant flux values reproduced the measured values in a satisfying way. Discrepancies in the relative shapes between measured and simulated emission spectra were found and attributed to multiple reflections within the phosphor layer. The interaction between the phosphors in PC-LEDs with phosphor mixtures was identified based on the emission spectra. The present simulation method (Figure 1.) turned out to be usable to optimize the target parameters of the PC-LED (luminous efficacy, white tone quality and color quality of the illuminated colored objects). A successful simulation allows scientists and engineers to save time when building optimized PC-LED light sources for research and development.

Competing interests

The authors declare that they have no competing interests.

Authors' contributions

All authors read and approved the final manuscript.

Acknowledgements

This work is supported by Technische Universität Darmstadt and Merck KGaA. 


\section{References}

1. Zukauskas A, Shur M, Gaska R: Introduction to solid state lighting. New York: John Wiley \& Sons; 2002.

2. Schubert EF, Kim JK, Luo H, Xi JQ: Solid-state lighting-a benevolent technology. Rep Prog Phys 2006, 12:69.

3. Chang MH, Das D, Varde PV, Pecht M: Light emitting diodes reliability review. Microelectron Reliab 2012, 5:52.

4. Sheu JK, Chang SJ, Kuo CH, Su YK, Wu L, Lin YC: White-light emission from near UV InGaN-GaN LED chip precoated with blue/green/red phosphors. Photonics Technol Let, IEEE 2003, 1:15.

5. Ye S, Xiao F, Pan YX, Ma YY, Zhang QY: Phosphors in phosphor-converted white light-emitting diodes: recent advances in materials, techniques and properties. Mat Sci Eng: R: Rep 2010, 1:71.

6. Chen L, Chu Cl, Liu RS: Improvement of emission efficiency and color rendering of high-power LED by controlling size of phosphor particles and utilization of different phosphors. Microelectron Reliab 2012, 5:52.

7. You JP, Shi FG: Effect of phosphor particle size on luminous efficacy of phosphor-converted white LED. J Lightwave Technol 2009, 22:27.

8. Huang SC, Wu JK, Hsu WJ, Chang HH, Hung HY, Lin CL, Liu RS: Particle size effect on the packaging performance of YAG: Ce phosphors in white LEDs. Int J App/ Ceram Technol 2009, 4:6.

9. Bois C, Bodrogi P, Khanh TQ, Winkler H: White LED light characteristics as a function of phosphor particle size. ECS J Solid State Sci Technol 2012, 5:1.

10. Bodrogi PZ: Semantic interpretation of the colour binning of white and coloured LEDs for automotive lighting products. In $10^{\text {th }}$ International Symposium on Automotive Lighting, September 2013. Edited by Herbert U. Darmstadt: Verlag; 2013:679.

11. Davis W, Ohno Y: Color quality scale. Opt Eng 2010, 49:3

12. Chen L, Lin CC, Yeh CW, Liu RS: Light converting inorganic phosphors for white light-emitting diodes. Mater 2010, 3:3.

13. Setlur AA, Srivastava AM: On the relationship between emission color and $\mathrm{Ce}^{3+}$ concentration in garnet phosphors. Opt Mater 2007, 12:29.

14. Lin CC, Liu RS: Advances in phosphors for light-emitting diodes. J Phys Chem Lett 2011, 11:2.

15. Khanh TQ, Bodrogi P, Vinh TQ, Brückner S: Farbwiedergabe von konventionellen und Halbleiter-Lichtquellen - Theorie. München: Bewertung, Praxis, Pflaum Verlag; 2013

16. Smet KAG, Schanda J, Whitehead L, Luo MR: CRI2012: a proposal for updating the CIE color rendering index. Lighting Res Technol 2013, 45:689-709.

doi:10.1186/2196-1107-1-5

Cite this article as: Bois et al:: Measuring, simulating and optimizing current LED phosphor systems to enhance the visual quality of lighting. Journal of Solid State Lighting 2014 1:5.

\section{Submit your manuscript to a SpringerOpen ${ }^{\circ}$ journal and benefit from:}

- Convenient online submission

Rigorous peer review

- Immediate publication on acceptance

- Open access: articles freely available online

- High visibility within the field

- Retaining the copyright to your article

Submit your next manuscript at $\gg$ springeropen.com 